\title{
Emotional After-effects of Change: Empirical Evidence from an Indian Organization
}

\author{
Chandranshu Sinha ${ }^{1}$ Ruchi Sinha ${ }^{2}$ \\ ${ }^{1}$ Assistant Professor, Amity Business School, Amity University Campus; F3 Block, Sector 125, Post Box-503, \\ Noida 201303 India \\ ${ }^{2}$ Assistant Professor, Galgotias Business School, 1, Knowledge Park, Phase II; Greater Noida 201306; Uttar \\ Pradesh, India
}

\begin{abstract}
The study explores employees' perception of emotional after-effects of change prevalent in an organization. Data of 100, at middle level, was collected from business process outsourcing organization, based in India. The Cronbach's alpha of the questionnaire was $0.797 \&$ Pearson correlation was $0.896(p<0.001)$. The factor analysis of 'emotional after-effects of organization change' led to the extraction of three factors. These factors were "Ignorance of Discord", "Dichotomy of Visibility" and "Kaleidoscopic Clarity" respectively. The results indicate that these factors give major cues in understanding the inner turmoil of employees at psychological level in the Indian context.
\end{abstract}

Keywords: Emotional After-Effects, Psychological Factors of Change, Emotional After-effects in Indian Context

\section{Introduction}

The study of emotions has been a relatively new but rapidly growing area of study within organizational research (Campbell, White, \& Johnson, 2003; Fineman, 2000, 2003; Madlock, 2008). Until quite recently the emotional behavior of organizational actors was thought to lie in the periphery of the organizational research but as employees increasingly find themselves in a work environment of ongoing organizational change (Albert et al., 2000; By, 2005; Kiefer, 2005) comprising of political, economic, social, and technological change, this shouldn't come as a surprise for individuals and groups working within them not getting affected. To search for conditions that promote successful change in organizations, it is crucial to know the emotional after effects it has on the employees. In a work environment characterized by organizational change, it may be particularly relevant to explore employees' emotional experiences, as emotions are assumed to be triggered when something of personal significance is perceived to interrupt or improve a smoothly flowing situation (BenZe'ev, 2001); when a situation or event is experienced to be of relevance or importance to the individual, such as when values, needs, and goals are affected (Lazarus, 1991); or when an event is seen as critical and/or substantial (Cox, 1997).

The managerial and change literature on emotional change-experiences has typically emphasized universal explanations focusing on affective states such as stress, satisfaction or boredom, or just positive or negative feelings (Fineman, 2000). It has been assumed that emotional responses occur in predictable and distinct stages throughout a change process, where the initial news of change is experienced negatively (resistance); that this experience is followed by an additional 'dip', characterized by an increased frequency and intensity of negative experiences/reactions and decreased work performance; and finally that a sense of normality, growth and increased efficiency will be resumed as change is eventually embraced by employees (Elrod and Tippett, 2002). Further Giaever (2009) has talked about anticipative versus retrospective emotional change-experiences arguing that organizational change is likely to be interpreted as more or less significant, important, or critical at different times in the change process; and hence that different emotional experiences may emerge at different times as change unfolds (Fineman, 2004). However the existing literature on employees' emotional change-experiences, as they manifest themselves at different points in time, is limited in its lack of acknowledgement of context. 'Context' has been defined in many ways (Johns, 2006); but the central idea is that external events, situations, and relationships (context) are seen as being part and parcel of, and hence giving meaning to, individual experiences and responses (Jaeger and Rosnow, 1988).

However, it is worth noting that current theoretical understanding on the nature, antecedents and consequences of employee's emotional after effects of change (in our context, after acquisition) are based largely on studies conducted in Western countries and although the organizational emotional research area is broad, it has not been extensively studied in the Indian context. The starting point for this research is the challenge of understanding employee's "emotional after-effects" of change in organizations. Managing organizational change is problematic: situations in which changes are undertaken are shifting; it is harder for organizations, and in particular top managers as well as change agents, to prepare for 'right' affect and manage 
the change in ways that satisfy the demands of both the organization and its employees (Meyer and Rowan 1977). To fill the above knowledge gap, in this study we examine the emotional after-effects of change (here in our context, after the acquisition process) that manifests itself in various forms, including: self efficacy of emotions, surface acting-emotion work, deep acting-emotion work, work attitude, emotional dissonance, mixed emotions, emotional exhaustion. These manifestations were examined on a group of professional managers in India, a society that is characterized by high uncertainty avoidance (Hofstede, 1980).

Theoretically, the paper contributes in two ways. First, this study examines the reasons behind what employees feel about emotional after-effects of change in Indian organizations. Second, the emerging factors of emotional after-effects of change identified here add to existing literature experienced by managers in organizations, especially in the Indian context. In this study, we focus on exploring this phenomenon of emotional after-effects of change that employees sense and feel in the Indian business process outsourcing sector. In other words, this research examines the reasons behind what the employees perceive about emotional after-effects of change prevalent in middle, lower and upper managerial level in an organization that has recently been acquired by a leading business process outsourcing giant, recognized as a rank holder in Data Quest's listing of the top 20 business process outsourcing companies in India for 2010-11. Thus, we propose that understanding the reasons behind employee's "emotional after-effects" of change for organizations is an important goal to critically analyze how managers sense and feel these phenomena, with effects on their behavior. A brief introduction and review of these seven manifestations of emotional after-effects of change that employees experience examined in this study are provided in the following section.

\section{Self-efficacy of Emotions}

\section{Literature Review}

The perception of being in control of the situation is often referred to as self efficacy (Bandura, 1982). Self efficacy is defined as a self-evaluation of one's competence to successfully execute a course of action that is necessary to reach desired outcomes (Bandura, 1993). Self efficacy is proven to have an impact on the way people think, feel, and act. Persons with low self efficacy have low self esteem, and are pessimistic about their accomplishments. Low self efficacy is associated with feelings of depression, anxiety and helplessness (Bandura, 1997). In relation to dealing with change, low self esteem and pessimism as well as insecurity have been proposed to have a direct influence on psychological stress (Bandura, 1982; 1993; 1997). Therefore, it is suggested that self efficacy is related to psychological job stress. Berneth (2004) identifies self-efficacy as an important factor for the success of change. One of the properties of self efficacy is that it is domain related. A person can have high self efficacy on one domain, and low self efficacy on another (Bandura, 1982). For example, one can have high self efficacy on carrying out academic tasks, but low self efficacy of job skills (Zajacova et al., 2005). A relevant domain in this study concerns self efficacy in terms of handling changes. That is, self efficacy is the perception of one's capabilities to handle changes. In other words, self efficacy is defined as the perceived ability to handle the rapidly changing situation due to a difficult situation. Self efficacy will be referred to as self efficacy of change. Self-efficacy continues to be seen as a pervasive driver and outcome of cognitive functioning in organizations, influencing positively learning (Chen et al. 2000), cognitive, affective-motivational and behavioral training outcomes (Colquitt et al. 2000), and responses to organizational change (Wanberg \& Banas 2000). Despite this popularity, equivocality persists regarding the most appropriate way of conceptualizing task and context specific self-efficacy in relation to its putative antecedents and consequences and the higher order generalized self-efficacy construct (Chen et al. 2000, Yeo \& Neal 2006). In recent years, there has been marked interest in the emergence and effects of collective efficacy in organizational teams and groups (for a review, see Ilgen et al. 2005; see also Srivastava et al. 2006, Tasa et al. 2007).

\section{Surface Acting Emotion Work}

The management of displayed emotions according to the requirements of the job is referred to as emotion work (or 'emotional labour', Hochschild 1983). More specifically, emotion work signifies the regulation of a job incumbent's emotional display so the conveyed emotions are in line with those expected by customers and by the organization for meeting set service quality demands (Morris and Feldman 1996). These emotions should be expressed with consistency over time and across situations and clients, and independently of the job incumbent's actually felt emotions, mood or attitudes towards particular customers. Therefore, emotion work often necessitates the disguise or modification of the job holder's actual emotions in order to display the emotions required by one's job role (Ashforth and Humphrey 1993). The process of disguising one's actual feelings, which results in dissonance between true and displayed emotion (Tschan et al. 2005), is referred to as 'surface acting'. (Hochschild 1983). Surface acting involves the suppression of felt emotions combined with the adoption of an emotional mask; which is a process that imposes substantial strain, and is potentially psychologically and physically draining. In particular, Bozionelos and Kiamouthe (2008) indicated that frequent engagement in surface acting, that is the regular disguise of felt emotions, was especially emotionally taxing and is is detrimental to employees' well-being (Brotheridge and Grandey 2002). Surface acting has been considered 
as primary dimensions of emotion work, while frequency, intensity and variety have been considered as secondary dimensions, described as 'emotion-related role requirements' (Brotheridge and Lee 2003). Indeed, the identification of frequency, intensity and variety as dimensions of emotion work has been inconsistent and more recent than the identification of surface acting (Brotheridge and Grandey 2002; Grandey 2003). Therefore, it is reasonable to expect that these three secondary dimensions bear weaker and less consistent relationships with correlates and outcomes of emotion work.

\section{Deep Acting Emotion Work}

The process of modifying one's felt emotions in a way that actual and displayed emotions are in consonance with each other and with the expected emotion is referred to as 'deep acting' (Hochschild 1983). The literature stresses the difference between surface and deep acting, as in comparison to former, although the later requires effort from the part of the individual it normally results in greater alignment between actual and displayed emotions; hence, in a reduction in the respective dissonance. These differences between the two are critical as regards the ways in which they relate, or they are expected to relate, to outcomes of emotion work (Ashforth and Tomiuk 2000; Zapf 2002; Brotheridge and Lee 2003; Grandey 2003). Surface and deep acting have been considered as primary dimensions of emotion work, while frequency, intensity and variety have been considered as secondary dimensions, described as 'emotion-related role requirements' (Brotheridge and Lee 2003). Indeed, the identification of frequency, intensity and variety as dimensions of emotion work has been inconsistent and more recent than the identification of surface and deep acting (Brotheridge and Grandey 2002; Brotheridge and Lee 2003; Grandey 2003). Therefore, it is reasonable to expect that these three secondary dimensions bear weaker and less consistent relationships with correlates and outcomes of emotion work. However despite requiring effort too, deep acting leads to internalization of one's job role and, hence, reduces dissonance between felt and displayed emotions (Totterdell and Holman 2003). Further Bozionelos and Kiamouthe (2008) suggest that deep acting may become emotionally taxing if the individual also tries to experience intensely the emotions she/he tries to internalize, or if a large variety of emotions need to be internalized; because this will require the deployment of psychological resources in greater degree and in a multitude of occasions, respectively. Therefore, the interactions of surface and deep acting with the three secondary dimensions of emotion work should be tested for their relationship with emotional exhaustion.

\section{Work Attitude}

The relationship between emotion work and work attitudes has not been empirically investigated, as yet; although such a relationship has been speculated (Grandey, 2000). Bozionelos and Kiamouthe (2008) suggest that though emotional exhaustion has been theoretically considered as an outcome of emotion work after review, they found that limited empirical evidence concurs with this view. Logically, therefore, Bozionelos and Kiamouthe (2008) suggest that emotion work should relate to work attitudes. There are two reasons to expect such a relationship:

1) Work attitudes have been identified as an outcome of emotional exhaustion, which, in turn, has been treated as an outcome of emotion work. Therefore, emotion work should be indirectly related to work attitudes via its relationship with emotional exhaustion. In other terms, emotional exhaustion should mediate the relationship between emotion work and attitudes towards the job and the organization.

2) Secondly, imposition of strict emotional display rules on one's job may also reflect on the attitudes of the job incumbent towards the organization, negatively influencing one's commitment towards it and one's intentions to stay with it. This means that apart from the indirect relationship, via emotional exhaustion, there should also be a direct relationship between emotion work and attitudes towards the job and the organization. Therefore, the mediating role of emotional exhaustion in the relationship between emotion work and work attitudes should be only partial.

\section{Emotional Dissonance}

Emotional dissonance is a form of role conflict (Rafaeli \& Sutton, 1987), and the tension and conflict arising from emotional dissonance is associated with emotional exhaustion (Lewig \& Dollard, 2003); in fact, high levels of dissonance predict high levels of emotional exhaustion (Morris \& Feldman, 1997). Emotional exhaustion is a core component of burnout and closely resembles traditional stress reactions such as fatigue, jobrelated depression, psychosomatic complaints, and anxiety (Demerouti, Bakker, Nachreiner, \& Schaufeli, 2001). Thus, an understanding of emotional dissonance will contribute to the traditional stress literature. There are different conceptualizations of emotional dissonance. It is considered as the state of discomfort, unease, tension, or psychological strain due to discrepancies between felt and expressed emotions or due to the discrepancy between felt and organizationally desired emotions. For example, emotional dissonance is considered a consequence arising from performing emotional labor, when employees' expressed emotions do not coincide with their true, internal feelings (Diefendorff, Croyle, \& Gosserand, 2005; Heuven \& Bakker, 2003; Lewig \& Dollard, 2003; Simpson \& Stroh, 2004). It is also an antecedent of emotional labor, due to the discrepancy 
between felt emotions and organizationally desired emotions (Jansz \& Timmers, 2002; Zapf \& Holz, 2006). It can also simply be a dimension of emotional labor (Kruml \& Geddes, 2000). Though there are several interpretations of dissonance, researchers have agreed on the fact that emotional dissonance is a stressor that has harmful effects on both the employee and the organization. In the present study, emotional dissonance is conceptualized as the state of discomfort, unease, and tension due to the discrepancy between felt and expressed or between felt and organizationally desired emotions.

\section{Mixed Emotions}

Increasingly, researchers have begun to explore the nature of mixed emotional experiences with a stream of research examining whether people can feel positive and negative emotions simultaneously. Aaker, Drolet and Griffin (2008) suggests that mixed emotions can be experienced jointly (e.g., Andrade and Cohen 2007; Larsen et al. 2004), particularly during periods of transition (e.g., moving out of a college dorm) and when exposed to specific stimuli (e.g., watching the film Life Is Beautiful). Another stream of research has explored when people are likely to experience mixed emotions (e.g., Fong and Tiedens 2002; Levav and McGraw 2008; Williams and Aaker 2002). Further, Aaker, Drolet and Griffin (2008) reveals that cultural background, chronic individual differences, and situational factors can all moderate the likelihood that mixed emotions are felt. With mixed emotion experiences, the information people attend to online is a blend of positive and negative information. When people consider such mixed information, they often react with feelings of conflict and discomfort (Cacioppo, Gardner, and Berntson 1997). In fact, this discomfort can trigger coping strategies to reduce or resolve the feelings of conflict (Folkman et al. 1986). People often reappraise the elements that underlie their mixed emotions (Zanna and Cooper 1974), change certain emotions in real time via "deep acting" (Hochschild 1983), or recognize and accept the co-occurrence of positive and negative emotions (Larsen et al. 2001). In contrast, such felt conflict typically does not arise with unipolar emotions, even negative emotions (Williams and Aaker 2002). However, it is important to note that not all people feel conflicted when experiencing mixed emotions. The degree to which people are concerned with attitudinal consistency or the social desirability of their behaviors raises the likelihood that mixed emotions arouse discomfort (Festinger 1957/1962). More generally, whether a person feels discomfort when feeling mixed emotions appears to be contingent on a variety of individual differences [e.g., impulsivity (Ramanathan and Williams 2007) proclivity to think in abstract ways (Hong and Lee 2007). For example, Asian Americans are more likely to acknowledge and accept psychological contradiction compared to individuals from North America (Spencer-Rodgers et al. 2004). Consequently, Anglo- Americans are more likely to feel conflicted than Asian Americans are when viewing messages highlighting mixed emotions (e.g., both happiness and sadness; Williams and Aaker 2002).

\section{Emotional Exhaustion}

Emotional exhaustion signifies the experience of being strained and depleted of one's emotional, primarily, and physical, secondarily, resources (Maslach, Schaufeli and Leiter 2001). It is the most prominent facet of job burnout, the psychological syndrome that is connected with chronic exposure to stressful interpersonal encounters in the context of work (Maslach et al. 2001). The limited empirical research on emotion work has focused mostly on the relationship of emotional exhaustion with the primary dimensions of emotion work, surface and deep acting. Bozionelos and Kiamouthe's (2008) work is supportive of the conceptual distinction between surface and deep acting, and in line with the argument that surface acting is detrimental to employees' well-being (Brotheridge and Grandey 2002). Indeed, the available empirical reports indicate a positive relationship between the degree to which employees engage in surface acting and their levels of emotional exhaustion (Brotheridge and Grandey 2002; Brotheridge and Lee 2003; Grandey 2003; Totterdell and Holman 2003). On the other hand, that same research has failed to identify a relationship between deep acting and emotional exhaustion. Such a relationship has not been particularly expected in the respective literature because, as noted, despite requiring effort too, deep acting leads to internalization of one's job role and, hence, reduces dissonance between felt and displayed emotions (e.g. Brotheridge and Grandey 2002, p. 22; Grandey 2003; Brotheridge and Lee 2003; Totterdell and Holman 2003).

\section{Methodology}

This study used a descriptive survey design. The purpose of descriptive surveys, according to Ezeani (1998), is to collect detailed and factual information that describes an existing phenomenon. A thorough review of literature was conducted before selecting the topic of the study. In this study, we focused on understanding the employee's emotional after effects of change from a leading business process outsourcing organization that has acquired more than sixteen companies in a span of ten years and at the time of data collection (in June 2011) the organization was in talks with seven more companies for potential acquisition, as it aimed to touch $\$ 1$ billion in revenue by March 2012. The target populations of the study were 100 middle level managers who were selected, to participate because they were key linking pins and were being trained for employee engagement activities. Also members among this group are often called upon to assume expanded roles, functions and 
responsibilities under the mentoring program. Additionally, they are more likely to be responsible for implementing the management strategies as key linking pins. As a result, they are in better position to observe and experience the emotional after-effects of change in organizations. It is hoped that this would provide more realistic and reliable data and information about how managers sense and feel the emotional after-effects of change, with effects on their behavior. Therefore, the findings regarding this group adds another perspective to the management literature on emotional after-effects of change in a leading business process outsourcing giant and examining the reasons behind what employees construe in their minds. A total enumeration sampling technique was used to select 100 middle level managers.

\section{Instrument}

A set of seven measures were selected for the study after going through the literature. A structured questionnaire was constructed utilizing these seven measures: including: self efficacy of emotions, surface acting-emotion work, deep acting-emotion work, work attitude, emotional dissonance, mixed emotions, emotional exhaustion with appropriate instructions for each section of the questionnaire for the collection of data on the study. The questionnaire was specifically designed to accomplish the objectives of the study. The first section was supplemented by items based on the studies of Tasa et al., 2007; Bozionelos and Kiamouthe, 2008; Mishra and Bhatnagar, 2010; Aaker, Drolet and Griffin, 2008. To assess the validity of the questionnaire, expert judgment method was applied. So, the developed questionnaire, along with explanations regarding terms and concepts were presented to three university professors, six managers from the organization under study. As such, they were asked to express their views about its construct, content, formal appearance and writing model. Many inputs were given by them that were included while finalizing the questionnaire. It was also noticed that some of the questions needed revision along with some additions and deletions. The necessary amendments were then made and its content and construct validity were assured and finally confirmed by other experts. The questionnaire consisted of 40 items in which the perception of the participants was central. The items measured the participants' perception, work behaviors and attitudes towards emotional after effects of change prevalent in their organizations. All 40 items were scored on a five-point Likert scale ranging from 1 "I strongly disagree" to 5 "I strongly agree". Then, to determine the reliability of the questionnaire, it was sent to the organization under study. The questionnaire was filled out by the research community belonging to middle managerial level from the organization. After the mentioned questionnaires were filled out, the reliability of the questionnaire was determined using Cronbach's alpha and Pearson correlation. The overall reliability co-efficient of the modified instrument after the pilot survey yielded an $r=0.797$ cronbach alpha while Pearson correlation was 0.896 $(\mathrm{p}<0.001)$ showing that the questionnaire was reliable.

\section{Results}

Table 1 show some of the demographic characteristics of the respondents who participated in the research study. As it is indicated in the table, the study comprised of people with varying years of work experience for both the gender.

Table 1: Frequency distribution of the respondents in accordance with demographic characteristics.

$\underline{\text { Demographic factor }}$

1. Gender

2. Work Experience (Female)

\section{Frequency Percentage}

\begin{tabular}{|c|c|}
\hline Gender & Frequency $\%$ \\
\hline Female & 35 \\
\hline Male & 65 \\
\hline TOTAL & $\overline{100}$ \\
\hline Duration & Frequency \% \\
\hline 0-3 Yrs & 10 \\
\hline 4-6 Yrs & 8 \\
\hline 6-9 Yrs & 8 \\
\hline $\begin{array}{c}\text { More } \\
\text { than } 9 \text { Yrs }\end{array}$ & 9 \\
\hline$\overline{\text { TOTAL }}$ & 35 \\
\hline
\end{tabular}


Emotional After-effects of Change: Empirical Evidence from an Indian Organization

3. Work Experience (Male)

\begin{tabular}{|c|c|}
\hline Duration & Frequency \% \\
\hline 0-3 Yrs & 19 \\
\hline 4-6 Yrs & 15 \\
\hline 6-9 Yrs & 15 \\
\hline $\begin{array}{c}\text { More than 9 } \\
\text { Yrs }\end{array}$ & 16 \\
\hline TOTAL & 65 \\
\hline
\end{tabular}

Table 2 presents the means and standard deviations of the following parameters exhibiting a different levels of satisfaction for the various parameters on which they were questioned:

Table 2:Quantitative Analysis Based On Mean- SD Score

\begin{tabular}{|l|l|l|}
\hline Dimensions & Mean & SD \\
\hline Self Efficacy of Emotions & 2.13 & .704 \\
Surface Acting-Emotion Work & 2.45 & .664 \\
Deep Acting-Emotion Work & 3.80 & .637 \\
Work Attitude & 3.68 & .924 \\
Emotional Dissonance & 2.55 & .722 \\
Mixed Emotions & 2.05 & .399 \\
Emotional Exhaustion & 2.32 & .662 \\
\hline
\end{tabular}

Table 3 presents zero-order correlations among all the study variables. The correlations between all variables are moderate $(0.10<r<0.40)$ and therefore do not suggest any problem of multicollinearity.

Table 3: Quantitative Analysis Based On Pearson's Correlation

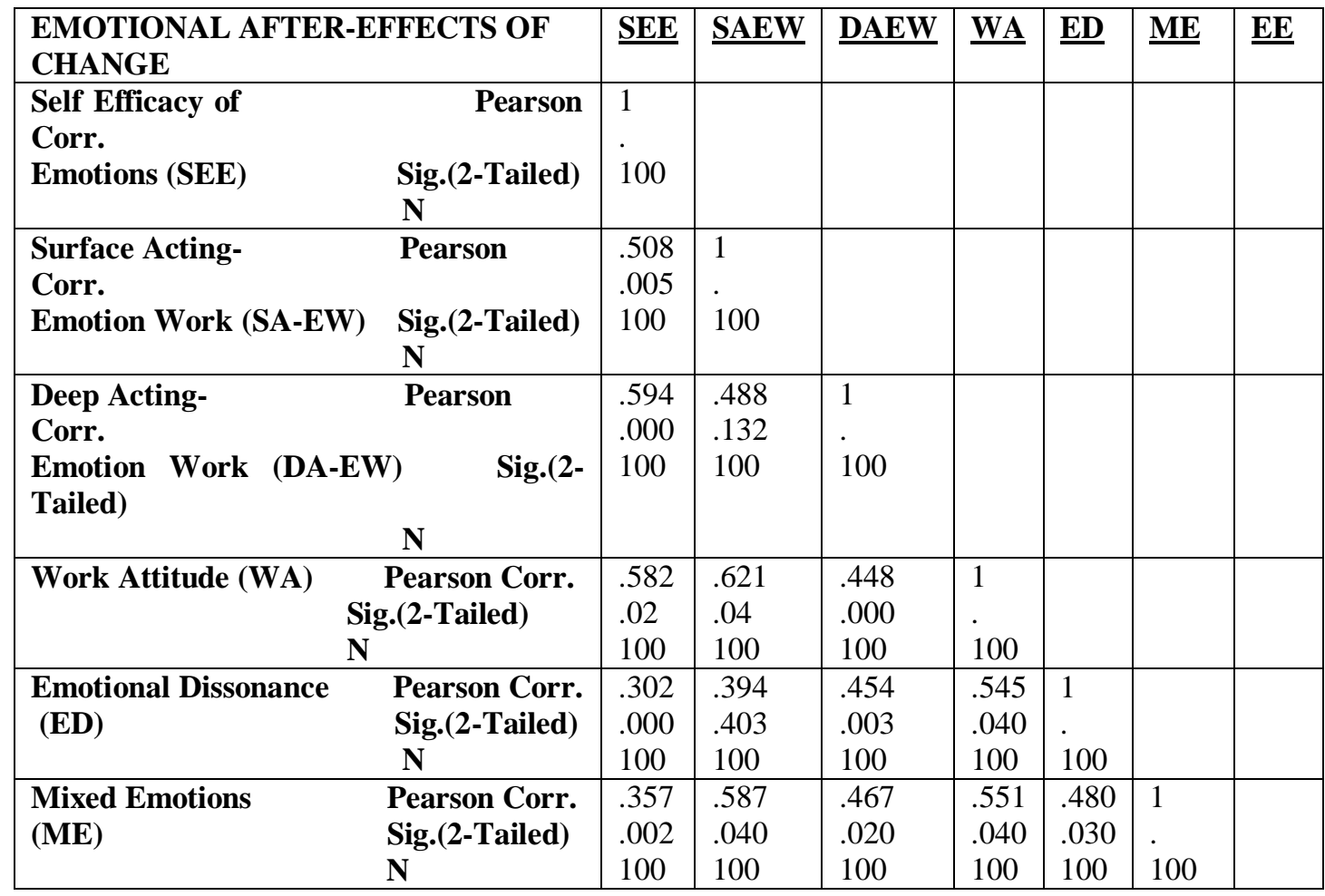


Emotional After-effects of Change: Empirical Evidence from an Indian Organization

\begin{tabular}{|lrr|l|l|l|l|l|l|l|}
\hline Emotional Exhaustion & Pearson & .628 & .566 & .542 & .446 & .436 & .443 & 1 \\
Corr. & & .003 & .000 & .050 & .030 & .002 & .432 &. \\
(EE) & Sig.(2- & 100 & 100 & 100 & 100 & 100 & 100 & 100 \\
Tailed) & & & & & & & & & \\
& $\mathbf{N}$ & & & & & & & & \\
\hline
\end{tabular}

After the correlation of each identified variable and the internal consistency of all variables were calculated in the component "Emotional After-effects of Change", the Kaiser-Meyer-Olkin approach was used to determine the sufficiency of the sample size for the component, while Bartlet test of sphericity was used to establish whether the correlation matrix has meaningful difference with zero or not. The sufficiency of sampling and meaningfulness of the correlation matrix was checked for the $(\mathrm{p}<0.001)$, respectively. It showed that the exploratory factor analysis was permissible. Then, the exploratory factor analysis was performed with maximum probability approach to identify the rate of loading of variables recognized in the component, and Varimax orthogonal approach was used to interpret the variables. The results showed that three factors came out from the "Emotional After-effects of Change" component with special values bigger than 1. The first, second and third factors explained $40.154,11.914$ and $10.810 \%$ of the total variances of variables, respectively. Therefore, these three factors explained $62.878 \%$ of the total variances of variables for the component "Emotional After-effects of Change".

As regards this component, the following variables formed the $1^{\text {st }}$ factor:

1) Emotional Dissonance

2) Mixed Emotion

The 2nd factor was formed by the following variables:

1) Emotional Exhaustion

2) Surface Acting-Emotion Work

The 3rd factor was formed by the following variables:

1) Work Attitude

2) Self Efficacy of Emotions

3) Deep Acting-Emotion Work

Table 4: $\quad$ Emotional After-effects of Change

$\begin{array}{llllll}\text { Code Variable } & \text { 1st factor } & \text { 2nd factor } & \text { 3rd factor } & \text { t-value } & \text { R2 } \\ \text { 1. Self Efficacy of Emotions } & & & 0.441 & 6.51^{*} & 0.64 \\ \text { 2. Surface Acting-Emotion Work } & & & 5.26^{*} & 0.45 \\ \text { 3. Deep Acting-Emotion Work } & & & .510 & 4.70^{*} & 0.41 \\ \text { 4. Work Attitude } & & 0.656 & 5.42^{*} & 0.58 \\ \text { 5. Emotional Dissonance } & 0.689 & & & 6.79 & 0.89 \\ \text { 6. Mixed Emotions } & 0.558 & & & 6.62 * & 0.20 \\ \text { 7. } & \text { Emotional Exhaustion } & 0.751 & & 5.68^{*} & 0.53\end{array}$

In Table 4, the confirmatory factor analysis was made with the use of Lisrel 8.7. Subsequent to the earlier stated stage, the first, second and third factors of the component, "Emotional After-effects of Change", were the approved factors named: "Ignorance of Discord", "Dichotomy of Visibility" and "Kaleidoscopic Clarity", respectively. Then the fitness of factors was achieved during the explanatory factor analysis in Table 5. The fitness indexes are as follows: Chi square index, goodness of fit index (GFI), comparative fit index (CFI), normed fit index (NFI), non-normed fit index (NNFI), incremental fit index (IFI), related fit index (RFI), adjusted goodness of fit index (AGFI), root mean square error of approximation (RMSEA) and root mean square residual (RMR). However, if CFI, GFI, NFI, NNFI, IFI, RFI and AGFI are higher than 0.90, and RMSEA and RMR are less than 0.50, it proves a desirable and appropriate fitness (Alexopoulos and Kalaitzidis, 2004). 
Emotional After-effects of Change: Empirical Evidence from an Indian Organization Table 5: Fitness index calculated for the component "Emotional After-effects of Change".

\begin{tabular}{|c|c|c|c|c|c|c|c|c|c|c|c|}
\hline $\begin{array}{l}\text { Compone } \\
\text { nt/Index }\end{array}$ & $\begin{array}{l}\text { Root } \\
\text { Mean } \\
\text { Square } \\
\text { error of } \\
\text { approx } \\
\text { (RMSEA) }\end{array}$ & $\begin{array}{l}\text { Good } \\
\text { ness } \\
\text { of Fit } \\
\text { Index } \\
\text { (GFI) }\end{array}$ & $\begin{array}{l}\text { Compa } \\
\text { rative } \\
\text { Fit } \\
\text { Index } \\
\text { (CFI) }\end{array}$ & $\begin{array}{l}\text { Norme } \\
\text { d Fit } \\
\text { Index } \\
\text { (NFI) }\end{array}$ & $\begin{array}{l}\text { Non- } \\
\text { Norme } \\
\text { d } \\
\text { Fit } \\
\text { Index } \\
\text { (NNFI) }\end{array}$ & $\begin{array}{l}\text { Incre } \\
\text { menta } \\
\text { l } \\
\text { Fit } \\
\text { Index } \\
\text { (IFI) }\end{array}$ & $\begin{array}{l}\text { Related } \\
\text { Fit } \\
\text { Index } \\
\text { (RFI) }\end{array}$ & $\begin{array}{l}\text { AG } \\
\text { FI }\end{array}$ & $\begin{array}{l}\mathbf{R M} \\
\mathbf{R}\end{array}$ & $\mathbf{X}^{2}$ & $\begin{array}{l}\mathbf{P} \\
\text { Value }\end{array}$ \\
\hline $\begin{array}{l}\text { Emotiona } \\
\text { l After } \\
\text { Effects of } \\
\text { Change }\end{array}$ & 0.0017 & 0.95 & 0.93 & 0.88 & 0.91 & 0.93 & 0.84 & $\begin{array}{l}0.7 \\
7\end{array}$ & $\begin{array}{l}0.03 \\
4\end{array}$ & $\begin{array}{l}22.1 \\
2\end{array}$ & $\begin{array}{l}p>0.0 \\
5\end{array}$ \\
\hline
\end{tabular}

\section{Discussion}

Findings of this research show that three factors each have been identified regarding emotional aftereffects of change. These factors highlight the fact that middle managers encounter different emotional aftereffects in India (a society that is characterized by high uncertainty avoidance, high power distance, femininity, long-term orientation and collectivism Hofstede, 1980) than those applied to their western counterparts along with a pattern of consistent and inconsistent mindsets and stereotypes in the face of organizational change. Given such cultural differences, the findings on emotional after-effects obtained from studies conducted in the West (for example Zajacova et al., 2005; Colquitt et al. 2000; Wanberg \& Banas 2000; Bozionelos and Kiamouthe, 2008; Brotheridge and Lee 2003; Lewig \& Dollard, 2003; Demerouti, Bakker, Nachreiner, \& Schaufeli, 2001; Aaker, Drolet and Griffin 2008) may not be readily generalized in the Indian context. This study explores factors that are a major source of perceptions of emotional after-effects of change that employees sense and feel that define roles, relations and procedures of interaction affecting the overall behavior of the organization. The present study investigated an important, yet mostly unexplored issue relating to emotion work in the Indian cultural context that differs from the context in which research on emotion work has been carried out in the past. The findings of this study are relevant because emotional expressiveness is becoming part of the experience of doing business among organizations (Schultz, Hatch, \& Larsen, 2000), especially in developing economies such as India. While scholars have endorsed the importance of emotional management in the Indian context (D'Cruz \& Noronha, 2008), research on this important issue is relatively scant, perhaps nonexistent. This study explores factors that are a major source of emotional after-effects of change in the Indian context and indicates a unique amalgamation of emotional, inter-personal and organizational issues exemplifying the consequences of emotional after-effects at psychological level, which the employees perceive and experience at work place. The findings of this research proved that the components identified and the structural relations presented as regards the component, "emotional after-effects of change" were suitable. The factors emerging from "emotional after-effects of organization change" also indicate that in technology-driven business environment, with ever increasing complexity, Indian workforce has undergone a tremendous transformation with individuals perceiving and prioritizing different degrees of challenges leading to a range of unique and culture-specific psychological variants of emotional after-effects of change. Based upon an understanding of peoples' perception of emotional after-effects of change, management can identify the strategic gaps (if any) to explain, prepare for 'right' affect, predict the behavior of people in organizations and manage the change in ways that satisfy the demands of both the organization and its employees (Meyer and Rowan 1977). In other words, organizations can take necessary actions to derive psychologically sound solutions to the unprecedented burdens confronting the twenty-first century workforce.

\section{Reference}

[1] Aaker, Drolet and Griffin (2008). Recalling Mixed Emotions. Journal of Consumer Research, Inc. Vol. 35 August 2008

[2] Albert, S., Ashforth, B.E. and Dutton, J.E. (2000) Organisational identity and identification: charting new waters and building new bridges, Academy of Management Review, 25, pp. 13-17.

[3] Andrade, Eduardo B. and Joel B. Cohen (2007), "On the Consumption of Negative Feelings," Journal of Consumer Research, 34 (October), 283-300.

[4] Ashforth, B.E., and Humphrey, R.H. (1993), "Emotional Labor in Service Roles: The Influence of Identity," Academy of Management Review, 18, 88-105.

[5] Ashforth, B.E., and Tomiuk, M.A. (2000), "Emotional Labour and Authenticity: Views from Service Agents," in Emotion in Organization (2nd ed.). ed. S. Fineman, London: Sage, pp. 184-203.

[6] Bandura, A. (1982). Self-Efficacy Mechanism in Human Agency. Amarican Psychologist , 37 (2), $122-147$

[7] Bandura, A. (1993). Perceived Self-Efficacy in Cognitive. Educational psychologist, 28 (2), 117-148.

[8] Bandura, A. (1997). Self-efficacy: The exercise of control. New York: Freeman.

[9] Ben-Ze'ev, A. (2001) The Subtlety of Emotions (London: The MIT Press).

[10] Berneth, J. (2004). Expanding our understanding of the change message. Human resource development review , 3 (1), $36-52$.

[11] Bozionelos and Kiamouthe (2008) Emotion work in the Hellenic frontline services environment: how it relates to emotional exhaustion and work attitudes. The International Journal of Human Resource Management, Vol. 19, No. 6, June 2008, 1108-1130 
[12] Brotheridge, C.M., and Grandey, A.A. (2002), "Emotional Labor and Burnout: Comparing Two Perspectives of 'People Work'," Journal of Vocational Behavior, 60, 17-39.

[13] Brotheridge, C.M., and Lee, R.T. (2003), "Development and Validation of the Emotional Labour Scale,"

[14] Journal of Occupational and Organizational Psychology, 76, 365-379.

[15] By, R.T. (2005) Organisational change management: a critical review, Journal of Change Management, 5(4), pp. 369-380.

[16] Cacioppo, John T., Wendi L. Gardner, and Gary C. Berntson (1997), "Beyond Bipolar Conceptualizations and Measures: The Case of Attitudes and Evaluative Space," Personality and Social Psychology Review, 1 (1), 3-25.

[17] Campbell, K. S., White, C. D., \& Johnson, D. E. (2003). Leader-member relations as a function of rapport management. Journal of Business Communication, 40, 170-194.

[18] Chen G, Gully S. M, Whiteman J. A, Kilcullen R. N. 2000. Examination of relationships among trait-like individual differences, state-like individual differences, and learning performance. Journal of Applied Psychological. 85:835-47

[19] Colquitt J. A, LePine J.A, Noe R. A. 2000. Toward an integrative theory of training motivation: a meta-analytic path analysis of 20 years of research. Journal of Applied Psychol. 85:678-707

[20] Cox, J. (1997) Manufacturing the past: loss and absence in organisational change, Organisation Studies, 18, pp. 623-654.

[21] D'Cruz, P., \& Noronha, E. (2008). Doing emotional labour: The experiences of Indian call centre agents.

[22] Global Business Review, 9(1), 131-147.

[23] Demerouti, E., Bakker, A. B., Nachreiner, F., \& Schaufeli, W. B. (2001). The job demands-resources model of burnout. Journal of Applied Psychology, 86(3), 499-512.

[24] Diefendorff, J. M., Croyle, M. H., \& Gosserand, R. H. (2005). The dimensionality and antecedents of emotional labor strategies. Journal of Vocational Behavior, 66(2), 339-357.

[25] Elrod, P.D. and Tippett, D.D. (2002) The ‘death valley’ of change, Journal of Organizational Change Management, 15, pp. 273291.

[26] Ezeani, S.I. (1998). Research methods: A realistic approach. Ibadan: Elohim Publishers.

[27] Festinger, Leon (1957/1962), A Theory of Cognitive Dissonance, Stanford, CA: Stanford University Press.

[28] Fineman, S. (Ed.) (2000). Emotion in organizations (2nd ed.). London: Sage.

[29] Fineman, S. (2003). Understanding emotions at work. London: Sage.

[30] Fineman, S. (2004) Understanding Emotion at Work (London: Sage Publications).

[31] Folkman, Susan, Richard S. Lazarus, Christine Dunkel-Schetter, Anita DeLongis, and Rand J. Gruen (1986), "Dynamics of a Stressful Encounter: Cognitive Appraisal, Coping, and Encounter Outcomes," Journal of Personality and Social Psychology, 50 (5), 992-1003.

[32] Fong, Christina T. and Larissa Z. Tiedens (2002), "Dueling Experiences and Dual Ambivalences: Emotional and Motivational Ambivalence of Women in High Status Positions," Motivation and Emotion, 26 (March), 105-21.

[33] Giæver, F. (2009) Looking Forwards and Back: Exploring Anticipative Versus Retrospective Emotional Change-Experiences, Journal of Change Management Vol. 9, No. 4, 419-434.

[34] Grandey, A. (2000), "Emotion Regulation in the Workplace: A New Way to Conceptualize Emotional Labor," Journal of Occupational Health Psychology, 5, 95-100.

[35] Grandey, A.A. (2003), "When 'The Show Must Go On': Surface Acting and Deep Acting as Determinants of Emotional Exhaustion and Peer-rated Service Delivery," Academy of Management Journal, 46, 86-96.

[36] Heuven, E., \& Bakker, A. (2003). Emotional dissonance and burnout among cabin attendants. European Journal of Work \& Organizational Psychology, 12(1), 81-100.

[37] Hochschild, A.R. (1983), The Managed Heart: Commercialization of Human Feeling, Berkeley, CA: University of California Press.

[38] Hofstede, G. (1980) Culture's Consequences: International Differences in Work-related Values. London: Sage.

[39] Hong, Jiewen and Angela Y. Lee (2007), "When Does the Coexistence of Pleasure and Pain Not Bother Us? Construal Level and Persuasiveness of Mixed Emotional Appeals," Northwestern Kellogg Working Paper, Evanston, IL.

[40] Ilgen D. R,, Hollenbeck J. R, Johnson M., Jundt D. 2005. Teams in organizations: from input process-output models to IMOI models. Annual Review Psycholgical. 56:517-43

[41] Jaeger, M.E. and Rosnow, R.L. (1988) Contextualism and its implications for psychological inquiry, British Journal of Psychology, 79, pp. 63-75.

[42] Jansz, J., \& Timmers, M. (2002). Emotional dissonance: When experience of emotions jeopardizes individuals' identity. Theory \& Psychology, 12(1), 79-95.

[43] Johns, G. (2006) The essential impact of context on organizational behaviour, Academy of Management Review, 31, pp. $386-408$.

[44] Kiefer, T. (2005) Feeling bad: antecedents and consequences of negative emotions in ongoing change, Journal of Organisational Behaviour, 26, pp. 875-897.

[45] Kruml, S., \& Geddes, D. (2000). Catching fi re without burning out: Is there an ideal way to perform emotion labor? In N. M. Ashkanasy, C. E. J. Hartel, \& W. J. Zerbe (Eds.), Emotions and organizational life (pp. 177-188). London: Quorum Books.

[46] Larsen, Jeff, Peter McGraw, and John T. Cacioppo (2001), "Can People Feel Happy and Sad at the Same Time?" Journal of Personality and Social Psychology, 81 (October), 684-96.

[47] Larsen, Jeff, Peter McGraw, Barbara Mellers, and John Cacioppo (2004), "The Agony of Victory and Thrill of Defeat: Mixed Emotional Reactions to Disappointing Wins and Relieving Losses," Psychological Science, 15 (5), 325-30.

[48] Lazarus, R.S. (1991) Emotion and Adaptation (New York: Oxford University Press).

[49] Levav, Jonathon and Peter McGraw (2008), "Emotional Accounting: Feelings about Money and Consumer Choice," Journal of Marketing Research, forthcoming.

[50] Lewig, K. A., \& Dollard, M. F. (2003). Emotional dissonance, emotional exhaustion and job satisfaction in call centre workers. European Journal of Work and Organizational Psychology, 12(4), 366-392.

[51] Madlock, P. E. (2008). The link between leadership style, communication competence, and employee satisfaction. Journal of Business Communication, 45, 61-78.

[52] Maslach, C., Schaufeli, W.B., and Leiter, M.P. (2001), “Job Burnout,” Annual Review of Psychology, 52, 397-422.

[53] Meyer, J. W., \& Rowan, B. (1977). Institutionalized organizations: Formal structure as myth and ceremony. American Journal of Sociology, 83: 340-363.

[54] Mishra, S.K. and Bhatnagar, D., (2010). Linking Emotional Dissonance and Organizational Identification to Turnover Intention and Emotional Well-Being: A Study of Medical Representatives in India. Human Resource Management, May-June 2010, Vol. 49, No. 3, Pp. 401-419_@ 2010 Wiley Periodicals, Inc. Published online in Wiley InterScience (www.interscience.wiley.com). DOI: $10.1002 / \mathrm{hrm} .20362$ 


\section{Emotional After-effects of Change: Empirical Evidence from an Indian Organization}

[55] Morris, J.A., and Feldman, D.C. (1996), "The Dimensions, Antecedents, and Consequences of Emotional Labor," Academy of Management Review, 21, 986-1001.

[56] Morris, J. A., \& Feldman, D. C. (1997). Managing emotions in the workplace. Journal of Managerial Issues, 9(3), 257-274.

[57] Rafaeli, A., \& Sutton, R. I. (1987). Expression of emotion as part of the work role. Academy of Management Review, 12(1), $23-$ 37.

[58] Ramanathan, Suresh and Patti Williams (2007), "Immediate and Delayed Emotional Consequences of Indulgence: The Moderating Influence of Personality Type on Mixed Emotions," Journal of Consumer Research, 34 (August), 212-23.

[59] Schultz, M., Hatch, M. J., \& Larsen, M. H. (2000). Introduction: Why the expressive or ganization? In M. Schultz, M. J. Hatch, \& M. H. Larsen (Eds.), The expressive organization: Linking identity, reputation, and the corporate brand (pp. 1-7). Delhi, India: Oxford University Press.

[60] Simpson, P. A., \& Stroh, L. K. (2004). Gender differences: Emotional expression and feelings of personal

[61] inauthenticity. Journal of Applied Psychology, 89(4), 715-721.

[62] Spencer-Rodgers, Julie, Kaiping Peng, Lei Wang, and Yubo Hou (2004), "Dialectical Self-Esteem and East-West Differences in Psychological Well-Being," Personality and Social Psychology Bulletin, 30 (November), 1416-32.

[63] Srivastava A, Bartol K. M, Locke E. A. 2006. Empowering leadership in management teams: effects on knowledge sharing, efficacy, and performance. Acad. Manage. J. 49:1239-51

[64] Tasa K,, Taggar S, Seijts, GH. 2007. The development of collective efficacy in teams: a multilevel and longitudinal perspective. J. Appl. Psychol. 92:17-27

[65] Totterdell, P., and Holman, D. (2003), "Emotion Regulation in Customer Service Roles: Testing a Model of Emotional Labor," Journal of Occupational Health Psychology, 8, 55-73.

[66] Tschan, F., Rochat, S., and Zapf, D. (2005), "It's Not Only Clients: Studying Emotion Work with Clients and Co-workers with an Event-sampling Approach,” Journal of Occupational and Organizational Psychology, 78, 195-220.

[67] Wanberg C. R., Banas J. T. 2000. Predictors and outcomes of openness to changes in a reorganizing workplace. J. Appl. Psychol. 85:132-42

[68] Williams, Patti and Jennifer Aaker (2002), “Can Mixed Emotions Peacefully Co-Exist?” Journal of Consumer Research, 28 (March), 636-49.

[69] Yeo G. B, Neal A. 2006. An examination of the dynamic relationship between self-efficacy and performance across levels of analysis and levels of specificity. J. Appl. Psychol. 91:1088-101

[70] Zanna, Mark P. and Joel Cooper (1974), "Dissonance and the Pill: An Attribution Approach to Studying the Arousal Properties of Dissonance," Journal of Personality and Social Psychology, 29 (5), 703-9.

[71] Zajacova, A., Lynch, S., \& Espenshade, T. (2005). Self-efficacy, stress, and academic success in college. Research in Higher Education , 46 (6), 677-706.

[72] Zapf, D. (2002), "Emotion Work and Psychological Well-being: A Review of the Literature and some Conceptual Considerations," Human Resource Management Review, 12, 237-268.

[73] Zapf, D., \& Holz, M. (2006). On the positive and negative effects of emotion work in organizations. European Journal of Work and Organizational Psychology, 15(1), 1-28. 